\title{
Immunotherapy in gynecological cancers
}

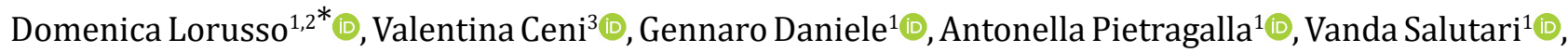

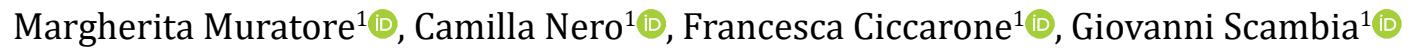 \\ ${ }^{1}$ Division of Gynecologic Oncology, Fondazione Policlinico Universitario Agostino Gemelli IRCCS, Largo Agostino Gemelli 8, \\ 00168 Rome, Italy \\ ${ }^{2}$ Department of Life Science and Public Health, Università Cattolica del Sacro Cuore, 00168 Rome, Italy \\ ${ }^{3}$ Department of Gynecology and Obstetrics, University of Parma, 43126 Parma, Italy
}

*Correspondence: Domenica Lorusso, Division of Gynecologic Oncology, Fondazione Policlinico Universitario Agostino Gemelli IRCCS, Largo Agostino Gemelli 8, 00168 Rome, Italy. domenica.lorusso@policlinicogemelli.it

Academic Editor: Rossana Berardi, Università Politecnica Marche, Italy

Received: July 29, 2020 Accepted: January 4, 2021 Published: February 28, 2021

Cite this article: Lorusso D, Ceni V, Daniele G, Pietragalla A, Salutari V, Muratore M, et al. Immunotherapy in gynecological cancers. Explor Target Antitumor Ther. 2021;2:48-64. https://doi.org/10.37349/etat.2021.00033

\begin{abstract}
Immunotherapy has changed the natural history of several malignancies that, a decade ago, had a very poor prognosis, such as lung cancer and melanoma. Consequently, many attempts have been done to expand the indications of immunotherapy agents, predominantly immune checkpoint inhibitors (ICIs), in other cancers, including gynecological malignancies. Alongside promising results in cervical and endometrial neoplasms, there are not clear data on the benefit of ICIs as single agent or in combination with antiangiogenic agents in ovarian cancer (OC) and ongoing trials are focusing on combining ICIs with standard chemotherapy or PARP inhibitors. This chapter summarized the evidences of ICIs in gynecological malignancies and report the ongoing trials in cervical, endometrial and OC.
\end{abstract}

\section{Keywords}

Immunotherapy, ovarian cancer, endometrial cancer, cervical cancer

\section{Introduction}

In the last decade immunotherapy has revolutionized the course of several cancers, such as lung, melanoma, and urogenital cancers.

Immunotherapy essentially acts by boosting the endogenous immune system against tumor cells. Active immunotherapy works by stimulating the host's own immune system versus malignant cells through cancer vaccines, such as dendritic peptide-, cell-, RNA-, DNA-vaccines or oncolytic viruses. Passive immunotherapy consists in administering immune compounds produced exogenously, stimulating an anti-tumor immune response. The latter, includes immune checkpoint inhibitors (ICIs) and adoptive $\mathrm{T}$ cell therapy (ACT) [1]. 
To elude the immune system, tumor cells grow a locally immunosuppressed microenvironment, that down-regulate $\mathrm{T}$ cells activation by creating inhibitory pathways: these latter exploit cytotoxic T-lymphocyteassociated protein 4 (CTLA-4), and programmed death-ligand 1 (PD-L1) and its receptor [programmed death-1 (PD-1)/PD-L1]. CTLA-4 acts on regulatory T cells binding competitively B7.1 and B7.2 ligands expressed on antigen-presenting cells (APCs), and consequently preventing their binding with stimulatory receptor CD28: this eventually blocks the activation of cytotoxic $\mathrm{T}$ lymphocytes. The $\mathrm{T}$ cell activation regulation by CTLA-4 mainly occurs within secondary lymphoid organs [2].

PD-1 is a molecule expressed on the surface of activated T and B cells, which binds to PD-L1 and PD-L2: the first ligand, PD-L1, is expressed on non-hematopoietic cells, leukocytes and in non-lymphoid tissues; the second ligand, PD-L2, is expressed, instead, on monocytes and dendritic cells [3]. This different expression pattern of PD-L1 and PD-L2, and B7 molecules just described is behind the hypothesis that CTLA-4 acts first to induce tolerance, whereas PD-1 joins later for maintaining long-term tolerance [4].

Tumor cells, overexpressing PD-L1 and PDL-2, develop the capacity to promote PD-1 signaling in tumorinfiltrating CD4 and CD8 T cells, therefore creating a locally immunosuppressed microenvironment [2]. Thus, inhibiting the PD-1/PD-L1 pathway reinstates the immune response against tumors and constitutes the rationale for using immune checkpoint blockade agents (ICIs) in tumor management; some examples of PD-1 or PD-L1 agents are: pembrolizumab, nivolumab, dostarlimab and cemiplimab or atezolizumab, avelumab and durvalumab, respectively.

Differently, ACT consists in the reinfusion, into cancer patients, of lymphocytes (T cells), either allogenic or autologous, after in vitro activation and expansion. While such treatment won't induce immunological memory, it grants immediate protection, albeit in the short-term only. Several types of ACT therapies are available: tumor-infiltrating lymphocytes (TILs), natural killer (NK) cells, lymphokine-activated killer (LAK) cells, and, more recently, T cell receptors (TCRs) and chimeric antigen receptors (CARs), able to target a wide range of potential cellular types. TCRs are obtained from the patient's lymphocytes transfected with a viral vector carrying TCR genes, and may identify antigens derived specifically from a tumor-reactive T cell clone. CARs are modified membrane receptors, composed of an extracellular antibody single-chain variable fragment (scFv), a TCR-derived internal domain, and one or more intracellular co-stimulatory domains [5].

\section{Immunotherapy in cervical cancer (CC)}

Persistent HPV infection is the recognized cause of almost all CCs. HPV escapes the immune system in different ways: down regulation of MHC class I (by HPV-E7 protein), impairment of antigen presentation (by HPV-E5 protein), expression of immune suppressive factors and, most importantly, attracting immune cells that can inhibit the immune response through the indoleamine-pyrrole 2,3-dioxygenase (ID0) enzyme [6]. Several studies reported elevated rates of PD-1/PD-L1 expression in up to $80 \%$ of cervical tumors: hence, supporting immunotherapy could be decisive to restore the immune response against tumor in CC.

PD-1 inhibitor pembrolizumab (MK-3475) was firstly studied in KEYNOTE-028, a phase Ib trial enrolling 475 patients with PD-L1-positive advanced solid tumors [including cervical, endometrial and ovarian cancer (OC)]. Patients were administered pembrolizumab at a dose of $10 \mathrm{mg} / \mathrm{kg}$ every two weeks until disease progression or unacceptable toxicity or for a maximum of 2 years [7]. Twenty-four patients joined the CC cohort: overall response rate (ORR) was found to be $17 \%$ with a median duration of response (DoR) of 5.4 months and $13 \%$ of patients experienced stable disease (SD). Five patients reported grade 3 treatmentrelated adverse events (AEs) mainly consisting in cutaneous rush and proteinuria. No grade 4 AEs or deaths were observed [8].

In the same trial, $13 \%$ ORR was reported in the 24 patients with advanced endometrial cancer (EC) [9] and $11.5 \%$ ORR in the 19 patients with advanced OC [10].

Pembrolizumab was further investigated in KEYNOTE-158, a phase II, non-randomized, multi-cohort trial. Ninety-eight patients with recurrent or metastatic CC were treated with pembrolizumab $200 \mathrm{mg} \mathrm{q} 3 \mathrm{w}$, until unacceptable toxicity or disease progression. At a median follow-up of 10.2 months, ORR was $12.2 \%$, with three complete responses (CRs) and nine partial responses (PRs). The latter responses occurred 
in patients with PD-L1-positive tumors where 14.6\% ORR was registered and the median DoR was not reached; $65.3 \%$ of patients experienced treatment-related AEs (12.2\% grade $\geq 3)$, mainly hypothyroidism (10.2\%), decreased appetite (9.2\%), and fatigue (9.2\%) [11]. Based on this data, in June 2018 the FDA approved pembrolizumab for the treatment of advanced/recurrent, previously treated, CPS $\geq 1$ CC, with CPS being the ratio of PD-L1 staining cells (both tumor cells, and immune cells) to the total number of viable tumor cells $\times 100$.

Nivolumab is another PD-1 inhibitor that has been tested in HPV-related malignancies. In the CheckMate 358 trial nivolumab ( $240 \mathrm{mg}$ every 2 weeks) was tested in a population of heavily pretreated cervical, vulvar and vaginal cancer patients: the disease control rate (DCR) was $70.8 \%$ and the ORR was $20.8 \%$ (responses to therapy were only noted in the CC cohort with a ORR 26.3\%) [12].

The results of CheckMate 358 study, testing two combination regimens of nivolumab plus ipilimumab, a monoclonal antibody targeting CTLA-4, in advanced CC, were presented at ESMO Congress in 2019. Ninetyone patients with recurrent squamous cervical tumors, with or without prior systemic therapies, were randomly chosen to receive nivolumab at $3 \mathrm{mg} / \mathrm{kg}$ q2 weeks plus ipilimumab at $1 \mathrm{mg} / \mathrm{kg}$ q6weeks (Nivo3 + Ipi1) or nivolumab at $1 \mathrm{mg} / \mathrm{kg}$ plus ipilimumab at $3 \mathrm{mg} / \mathrm{kg}$, given $\mathrm{q} 3 \mathrm{w}$ for 4 doses followed by nivolumab at $240 \mathrm{mg} \mathrm{q} 2 \mathrm{w}$ (Nivo1 + Ipi3). In the Nivo1 + Ipi3 arm ORRs were higher both in the chemo-naive patients ( $46 \%$ vs. 32\%) and in patients with prior systemic therapy (36\% vs. 23\%). Similarly, median overall survival (OS) was 25.4 and 10.3 months with Nivo1 + Ipi3 and Nivo3 + Ipi1, respectively, in pretreated patients while was not reached in the chemo-naive population [13].

Besides the trials above mentioned (Table 1), ongoing trials are exploring the role of ICIs combined with chemo-radiation CX-11 [14], or neo-adjuvant chemotherapy MITO CERV 3 [15], in locally advanced disease, and in combination with systemic platinum-based chemotherapy in the advanced setting, either in chemo-naïve patients (KEYNOTE-826 [16] and BEAT-CC trial [17]) or in previously treated patients (CX-8 GEMAB [18] and CX-9 REGENERON trial [19]).

Table 1. Clinical trials in CC

\begin{tabular}{|c|c|c|c|c|c|c|}
\hline Author & Trial/Phase & Setting & Pts $N$ & Treatment & Results & $\begin{array}{l}\text { Grade 3-4 AEs } \\
\text { Pts } N(\%)\end{array}$ \\
\hline $\begin{array}{l}\text { Lheureux } \\
\text { et al., } \\
2015 \text { [25] }\end{array}$ & $\begin{array}{l}\text { NCT01693783 } \\
\text { Phase I-II }\end{array}$ & $\begin{array}{l}\text { Metastatic, } \\
\text { recurrent }\end{array}$ & 42 & $\begin{array}{l}\text { Ipilimumab } 10 \mathrm{mg} / \\
\mathrm{kg} \mathrm{q} 3 \mathrm{w} \text { for } 4 \text { cycles } \\
\text { If CR/PR/SD } 4 \rightarrow \\
\text { cycles ipilimumab } \\
10 \mathrm{mg} / \mathrm{kg} \mathrm{q} 12 \mathrm{w} \\
\text { every } 12 \text { weeks }\end{array}$ & ORR $8.8 \%$ & $\begin{array}{l}\text {-diarrhea } n=4 \\
(9.5) \\
\text {-colitis } n=3(7.1)\end{array}$ \\
\hline $\begin{array}{l}\text { Chung et } \\
\text { al., } 2019 \\
{[11]}\end{array}$ & $\begin{array}{l}\text { KEYNOTE-158 } \\
\text { Phase II }\end{array}$ & $\begin{array}{l}\text { PD-L1 positive } \\
\text { advanced }\end{array}$ & $\begin{array}{l}98(82, \\
\text { PDL1 } \\
\text { CPS } \geq 1)\end{array}$ & $\begin{array}{l}\text { Pembrolizumab } \\
200 \text { mg q3w }\end{array}$ & $\begin{array}{l}\text { ORR } 12.2 \% \\
\text { 14.6\% in PD-L1 positive } \\
\text { Total population: } \\
\text { Median PFS } 2.1 \text { Mo. } \\
\text { Estimated PFS rate at } \\
6 \text { Mo. } 25.0 \% \\
\text { Median OS } 9.4 \text { Mo. } \\
\text { 6-month estimates OS } \\
\text { 75.2\% } \\
\text { 12-month estimates } \\
\text { OS } 41.4 \% \\
\text { PD-L1 positive: } \\
\text { Median PFS } 2.1 \text { Mo. } \\
\text { Median OS } 11 \text { Mo. } \\
\text { 6-month estimates OS } \\
\text { 80.2\% } \\
\text { 12-month estimates }\end{array}$ & $\begin{array}{l}\text { Treatment related: } \\
\text {-increased ALT } \\
n=3(3.1) \\
\text {-increased AST } \\
n=2(2.0) \\
\text { Immune-mediated: } \\
\text {-hepatitis } n=2 \\
(2.0) \\
\text {-severe skin } \\
\text { reactions } n= \\
2(2) \\
\text {-adrenal } \\
\text { insufficiency } n= \\
1(1)\end{array}$ \\
\hline
\end{tabular}


Table 1. Clinical trials in CC (continued)

\begin{tabular}{|c|c|c|c|c|c|c|}
\hline \multirow[t]{2}{*}{ Author } & \multirow[t]{2}{*}{ Trial/Phase } & \multirow[t]{2}{*}{ Setting } & \multirow[t]{2}{*}{ Pts $N$} & \multirow[t]{2}{*}{ Treatment } & \multirow[t]{2}{*}{ Results } & \multirow{2}{*}{$\begin{array}{l}\text { Grade 3-4 AEs } \\
\text { Pts } N(\%)\end{array}$} \\
\hline & & & & & & \\
\hline \multirow{12}{*}{$\begin{array}{l}\text { Wendel } \\
\text { Naumann } \\
\text { et al., } \\
2019 \text { [12] }\end{array}$} & \multirow{12}{*}{$\begin{array}{l}\text { CheckMate } \\
358 \\
\text { Phase I-II }\end{array}$} & \multirow{12}{*}{$\begin{array}{l}\text { HPV-associated } \\
\text { tumors, } \\
\text { recurrent or } \\
\text { metastatic } \\
\text { cervical, } \\
\text { vaginal, vulvar } \\
\text { cancers }\end{array}$} & \multirow{12}{*}{$\begin{array}{l}24 \text { (19 } \\
\text { cervical, } \\
5 \text { vaginal- } \\
\text { vulvar } \\
\text { cancer) }\end{array}$} & \multirow{12}{*}{$\begin{array}{l}\text { Nivolumab } 240 \mathrm{mg} \\
\text { q2w }\end{array}$} & ORR: & \multirow{3}{*}{$\begin{array}{l}\text { Cervical cohort: } \\
\text {-diarrhea } n=1 \\
(5.3)\end{array}$} \\
\hline & & & & & 26.3\% (cervical) & \\
\hline & & & & & $20.0 \%$ (vaginal-vulvar) & \\
\hline & & & & & DCR: & $\begin{array}{l}\text {-hepatocellular } \\
\text { iniury } n=1(5-3)\end{array}$ \\
\hline & & & & & $68.4 \%$ (cervical) & -pneumonitis $n$ \\
\hline & & & & & $80.0 \%$ (vaginal-vulvar) & $=1(5.3)$ \\
\hline & & & & & Median PFS 5.1 Mo. & \multirow{6}{*}{$\begin{array}{l}\text { Vaginal/vulvar } \\
\text { cohort: } \\
\text { none }\end{array}$} \\
\hline & & & & & $\begin{array}{l}26.3 \% \text { progression free } \\
\text { patients at } 12 \mathrm{Mo} .\end{array}$ & \\
\hline & & & & & In cervical cohort: & \\
\hline & & & & & Median OS 21.9 Mo., & \\
\hline & & & & & $\begin{array}{l}\text { 12-month OS rate } \\
77.5 \%\end{array}$ & \\
\hline & & & & & $\begin{array}{l}\text { 24-month OS rate } \\
49.8 \%\end{array}$ & \\
\hline
\end{tabular}

Pts $N$ : patient number; PFS: progression free survival; Mo.: month

Given the immunomodulatory effects of bevacizumab, ICIs have also been combined with antiangiogetic drugs in order to capture a possible synergist effect of the association in advanced CC, where antiangiogenetic drugs are already licensed. The BEAT trial is investigating the combination of bevacizumabcisplatin-paclitaxel and atezolizumab in the first line CC metastatic disease.

In the context of ACT, Stevanović et al. [20], reported an ORR of 33\% after a single infusion of E6 and E7 reactive TIL and IL-2 (after lympho-depletion chemotherapy) in a population of heavily pretreated, advanced $\mathrm{CC}$; these promising results call for further investigation.

Finally, thanks to the success of prophylactic HPV vaccines in the prevention of cervical dysplasia, there is great drive to develop therapeutic HPV vaccines targeting E6 and E7 oncoproteins. The most promising of these appears to be the ADXS11-001, amalimo-gene-filolisbac: a live attenuated Listeria monocytogenes ( $\mathrm{Lm}$ ) vaccine containing E7 oncoprotein from HPV-16, ADXS11-001 is under evaluation in different trials, both as single agent (GOG/NRG-0265 [21]) or in combination with Durvalumab [22] or cisplatin [23].

Unfortunately, the results of the above mentioned trials are not strong enough to be cost-effective, especially in undeveloped countries where CC ranks second in incidence and its mortality is only behind breast cancer [24].

\section{Immunotherapy in EC}

EC patients are diagnosed at early-stage disease with a 5-year OS of $80 \%$, advanced stage patients present a dismal prognosis with 5-year survival of about $15 \%$ [26].

According to the Tumor Cancer Genome Atlas (TCGA) classification, EC subtypes with high tumor mutational burden, POLE mutant and microsatellite instability hypermutated (MSI-H) with a deficiency in the mismatch repair system (dMMR), are highly immunogenic: that is, they exhibit elevated tumor specific neoantigens, resulting in an enlarged number of $\mathrm{CD}^{+}$and $\mathrm{CD} 8^{+}$TILs and in a compensatory up regulation of immune checkpoints [27]. MSI-H is found in approximately 30\% of EC [28], 40-80\% of endometrioid, 10$68 \%$ of serous, and $23-69 \%$ of clear cell EC, which overexpressed PD-1/PD-L1, suggesting that the targeting of this pathway may constitute a hopeful strategy to increase antitumor immune response [29].

The FDA approval of pembrolizumab in solid tumors with MSI-H or dMMR, was "tumor agnostic" and based on data across five uncontrolled, multi-cohort, single-arm trials: a total of 149 patients with MSI-H were identified and in the 14 patients cohort of EC the ORR was 36\% [30]. 
In September 2019 FDA approved the combination of pembrolizumab plus lenvatinib for the treatment of advanced EC non harboring MSI-H, based on the results of KEYNOTE-146, a single-arm study in advanced EC patients progressing after at least one prior systemic chemotherapy line. Patients were treated with lenvatinib $20 \mathrm{mg}$ orally once per day in combination with pembrolizumab $200 \mathrm{mg}$ every 3 weeks, until progression of disease. Among 108 enrolled patients, 94 presented microsatellite stable or MSS (not MSI-H or dMMR) stable tumors, 11 had MSI-H tumors, and in 3 patients MSI status was not known. The ORR was 38.3\% with 10 CRs (10.6\%) and 26 PRs (27.7\%) in MSS cohort [31,32]. EMA indication is pending, waiting for the results of a randomized trial comparing Lenvatininb-pembrolizumab versus physician's choice chemotherapy in advanced setting.

PD-1 inhibitor nivolumab was investigated in a phase II study in a mixed cohort of patients at the dose of $240 \mathrm{mg}$ every 2 weeks. Preliminary results indicated an ORR of $22.7 \%$ in the EC cohort: notably, ORR was similar regardless of PD-L1 expression, with all patients with MSI-H tumors experiencing at least a PR [33].

In the GARNET trial, the PD-1 inhibitor dostarlimab (TSR-042) was assessed on a population of 94 advanced ECs at the dose of $500 \mathrm{mg}$ IV every 3 weeks for the first 4 cycles, followed by 1,000 mg IV every 6 weeks thereafter. The ORR was $27.7 \%$ (50\% in MSI-H tumors and $19.1 \%$ in MSS tumors) and the DCR was $48.9 \%$ [34]. At an update analysis, among 70 patients with MSI-H tumors, the ORR was $43 \%$ (9 patients had a confirmed CR and 21 had a PR) and the DCR was 59\% [35].

In a preliminary phase Ia study atezolizumab was administered at the dose of 1,200 mg q3weeks to 15 advanced EC patients reporting an ORR of $13 \%$ and a DCR of $26 \%$ without significant treatment related AEs; it is worth noting that in tumors presenting both elevated PD-L1 expression and TILs, the ORR appeared higher [36].

Recently, the combination of durvalumab with or without tremelimumab, a CTLA-4 inhibitor, was examined in 56 recurrent EC patients (NCT03015129). In the durvalumab monotherapy arm the ORR was $14.8 \%$ with $13.3 \%$ of patients not progressing at 24 -week, while in the combination arm the ORR was $11.1 \%$ with a 24 -week PFS of $18.5 \%$. Grade 3-4 treatment related AEs were $11 \%$ and $43 \%$ in the monotherapy and combination arm, respectively [37].

Besides the trials above mentioned (Table 2) there is a variety of ongoing trials evaluating the role of ICIs in EC either as single agents (NCT02899793 [38] and NCT02912572 [39]) or in combination with other ICIs [40] or chemotherapy in advanced disease, both in chemonaive (LEAP trial [41], AtTEND trial [42], Ruby trial [43], MITO END 3 [44]) or pretreated patients (NRG-GY018 [45], KEYNOTE-775 [46]).

Table 2. Clinical trials in EC

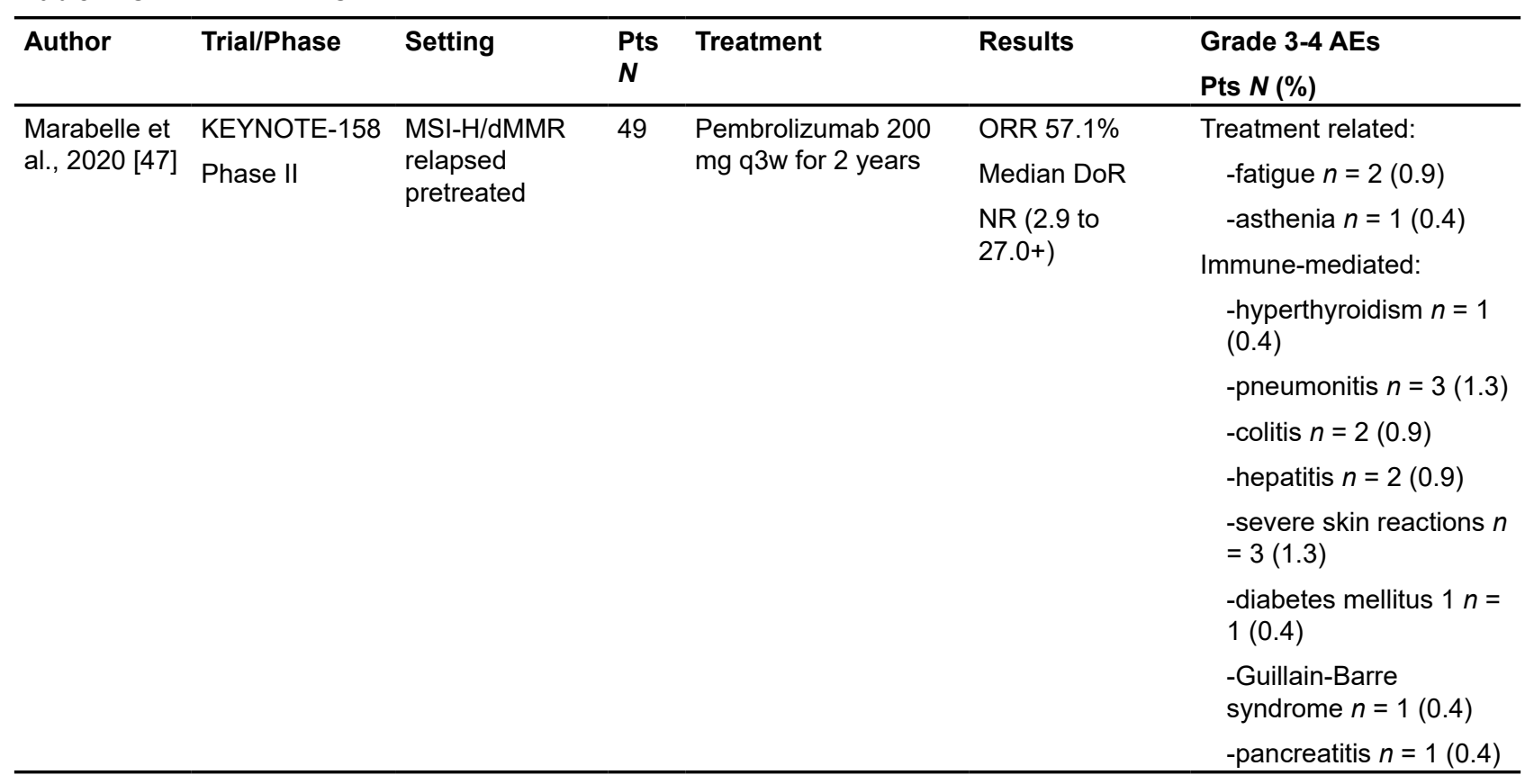


Table 2. Clinical trials in EC (continued)

\begin{tabular}{|c|c|c|c|c|c|c|}
\hline Author & Trial/Phase & Setting & $\begin{array}{l}\text { Pts } \\
N\end{array}$ & Treatment & Results & $\begin{array}{l}\text { Grade 3-4 AEs } \\
\text { Pts } N(\%)\end{array}$ \\
\hline $\begin{array}{l}\text { Makker et } \\
\text { al., } 2019 \text { [31] }\end{array}$ & $\begin{array}{l}\text { KEYNOTE } 146 \\
\text { Phase II }\end{array}$ & $\begin{array}{l}\text { Metastatic, no } \\
\text { more than two } \\
\text { prior systemic } \\
\text { therapies }\end{array}$ & 53 & $\begin{array}{l}20 \mathrm{mg} \text { oral lenvatinib } \\
\text { daily plus } 200 \mathrm{mg} \\
\text { pembrolizumab q3w }\end{array}$ & $\begin{array}{l}\text { ORR 39.6\% } \\
\text { investigator } \\
\text { review } \\
\text { ORR } 45.3 \% \\
\text { independent } \\
\text { review }\end{array}$ & $\begin{array}{l}\text { Treatment-related: } \\
\text { Grade 3: } n=36(68) \\
\text { Grade 4: none } \\
\text { Most common: } \\
\text {-hypertension } n=18 \\
(34) \\
\text {-diarrhoea } n=4(8) \\
\text {-palmar-plantar } \\
\text { erythrodysesthesia } \\
\text { syndrome } n=3(6)\end{array}$ \\
\hline $\begin{array}{l}\text { SGO } 2019 \\
\text { Annual } \\
\text { meeting [48] }\end{array}$ & $\begin{array}{l}\text { GARNET } \\
\text { Phase I }\end{array}$ & $\begin{array}{l}\text { Previously } \\
\text { treated } \\
\text { recurrent or } \\
\text { advanced }\end{array}$ & 110 & $\begin{array}{l}\text { Dostarlimab } 500 \mathrm{mg} \\
\text { q3w for } 4 \text { cycles } \rightarrow \\
1,000 \mathrm{mg} \mathrm{q6w}\end{array}$ & $\begin{array}{l}\text { ORR } 27.7 \% \\
\quad(50.0 \% \text { in } \\
\text { MSI-H; } 19.1 \% \\
\text { in MSS }) \\
\text { DCR } 48.9 \%\end{array}$ & $\begin{array}{l}\text { Treatment-related: } \\
\text { Grade } 3-4 n=1311.8 \% \\
\text { Most common: } \\
\text {-AST increased (2.7) }\end{array}$ \\
\hline
\end{tabular}

Pts N: patient number; NR not reached

\section{Immunotherapy in OC}

PD-L1 seems to be particularly expressed in OC cells compared to other neoplasms and it is known to result in worse survival. Moreover, having a high frequency of TILs and neoantigen load in select groups of patients, such as those presenting homologous recombination deficiency (HRD) or MSI-H OC represents a promising target for immunotherapy, therapeutic vaccines and ACT [49]. Nevertheless, no immunotherapy agent is yet approved in OC, so far, due to the unsatisfactory results from ICIs in any setting of disease.

KEYNOTE-100, a phase II trial, enrolling two cohorts of relapsed OC patients $(n=376)$ : cohort A recruiting women previously pretreated with 1-3 lines of chemotherapy with a treatment-free interval (TFI) of 3-12 months; and cohort B including patients with up to 6 prior lines and a TFI longer than 3 months. In the overall population the ORR was $8 \%$ and the DCR was $37 \%$; considering the two cohorts separately, ORR was $7.4 \%$ in cohort A and $9.9 \%$ in cohort B. Median PFS was 2.1 months in the overall population, and median OS was 18.7 months in cohort A and 17.6 months in cohort B (presented at ASCO annual meeting). The expression of PD-L1, evaluated using CPS score, showed an ORR of 5.0\%, in patients with CPS $<1$, whereas it was $10.2 \%$ if $\mathrm{CPS} \geq 1$ and $17.1 \%$ if $\mathrm{CPS} \geq 10$ [50].

In JAVELIN 200 trial 566 platinum resistant OC patients were randomized to receive pegylated liposomal doxorubicin (PLD), avelumab or the combination of both. Unfortunately, the combination of avelumab and PLD did not extend the median PFS (3.5 months vs. 3.7 months) and the median OS (13.1 months vs. 15.7 months) with respect to PLD single agent [51].

In a single arm phase II study 37 platinum resistant patients treated with the combination of weekly paclitaxel and pembrolizumab, reported an ORR of 51.4\%, a DCR of $86.5 \%$, with 6-month progression free in $64.5 \%$ of patients, a median PFS of 7.6 months and a median OS of 13.4 months [52].

The possibility of combining different ICIs was investigated in the NRG-GY003 trial: 100 patients with recurrent $\mathrm{OC}$ were randomized to receive nivolumab alone (arm 1), or the combination of nivolumab and ipilimumab, followed by nivolumab maintenance (arm 2). The platinum-free interval (PFI) stratified hazard ratio (HR) for PFS was 0.528 and the HR for death was 0.789 [53].

Despite the negative results in the recurrent setting, ICIs were investigated in first line treatment, based on the hypothesis that a less exhausted immune system in chemo naïve patients could possibly translate in a better efficacy of strategy.

Avelumab (Ave) was investigated in a phase III randomized trial with Ave and chemotherapy (CT), JAVELIN 100 trial, both in combination and maintenance (CT + Ave $\rightarrow$ Ave) or only as maintenance after 
carboplatin-paclitaxel (CT $\rightarrow$ Ave) in newly diagnosed, advanced OC; the control arm consisted in patients receiving placebo as maintenance ( $\mathrm{CT} \rightarrow 0$ ).

The study was prematurely terminated for futility at a median follow-up of 11 months; at the pre-planned interim analysis the PFS HR in CT $\rightarrow$ Ave arm vs. control was 1.43 and in CT + Ave $\rightarrow$ Ave arm vs. control was 1.14. The ORR were $30.4 \%, 36.0 \%$ and $30.4 \%$ for CT $\rightarrow$ Ave, CT + Ave $\rightarrow$ Ave and CT $\rightarrow 0$ arms respectively, with a significant increase in toxicity in both experimental arms [54].

Due to the deluding results of immunotherapy administered as monotherapy, researchers have explored the possibility of combining ICIs with parp inhibitors and antiangiogenic agents.

While HRD tumors are characterized by an elevated PD-L1 expression, probably because of the persistence of not lethal DNA defects that continuously stimulate innate immune cell to release proinflammatory substances, they are likely to escape immune control, switching from a Th1-immunity to a chronic inflammation and immunosuppression. Poly (ADP-ribose) polymerase inhibitors (PARPi), triggering a catastrophic DNA damage, especially in HRD cells, could, therefore, reestablish a productive Th1 immune response, thus readjusting the tumor microenvironment [55]. In BRCA mutated mouse models, PARPi increased the mutational tumor load and TILs and activated interferon-mediated pathway by synergizing with ICIs, consequently providing a strong case in favor of drug combinations [56].

The combination of a PARPi, olaparib, with a PD-L1 inhibitor, durvalumab, was the objective of investigation of a multi-cohort trial, called MEDIOLA. Platinum-sensitive recurrent OC patients' cohort, with a known or suspected deleterious germline BRCA1/2 mutation, received olaparib $300 \mathrm{mg}$ bid and durvalumab 1,500 mg every four weeks: the ORR was $71.9 \%$ (7 CRs) with a median DoR of 10.2 months and a 28-week DCR of 65.6\%; median PFS was 11.1 months and median OS was not reached, with $87.0 \%$ of patients alive at 24 months [57].

The TOPACIO/KEYNOTE-162 trial explored, in women with advanced or metastatic triple-negative breast cancer (TNBC) or recurrent OC, irrespective of $B R C A$ mutation status, the combination of pembrolizumab and niraparib. Among the 60 patients of the OC cohort, the ORR was $18 \%$ (3 CRs and 8 partial responses), with a DCR of $65 \%$ and a median DoR not reached (range, 4.2 to $\geq 14.5$ months); remarkably the ORR was found to be uniform among subgroups, divided in patients with platinum sensitive OC, pre-treated with Bevacizumab and BRCAmut or HRD [58].

Many ongoing clinical trials are exploring the potential advantages of combining PARPis with ICIs and antiangiogenic drugs in newly diagnosed OC (AGO DUO [59], ENGOT OV 43 [60], FIRST [61] and ATHENA trial [62], MITO 28 [63]), in combination and maintenance after first line carboplatin-paclitaxel chemotherapy.

The rationale for combining immunotherapy with antiangiogenic agents lies on the ability of the latter to enhance $\mathrm{T}$ cell trafficking and infiltration into the tumor microenvironment [64]: in preclinical models, the inhibition of vascular endothelial growth factor (VEGF) signaling promoted antitumor immunity and enhanced the efficacy of immune checkpoint blockade [65], moreover the combination of anti-VEGF and antiPD-L1 showed a synergistic anti-tumor effect in vivo [66]. This combination is under investigation both in first line and in platinum-sensitive and platinum-resistant relapses.

IMagyn050/GOG 3015/ENGOT-OV39 is a phase III randomized study evaluating the administration of atezolizumab/placebo in combination with carboplatin-paclitaxel-bevacizumab in 1,300 newly-diagnosed, stage III-IV OC patients [67].

The failing results of this trial were presented at the last ESMO Congress in 2020: PFS in the intentto-treat population (1,301 patients) was 19.5 months with the combination atezolizumab/bevacizumab/ chemotherapy versus 18.4 months with only bevacizumab and chemotherapy (HR, 0.92). In the PD-L1positive population $(n=784)$, the median PFS was 20.8 months vs. 18.5 months with the atezolizumab regimen and standard treatment respectively (HR, 0.80). However, results from exploratory PFS analyses demonstrated a trend supporting atezolizumab in patients with PD-L1 immune cells of 5\% or greater. Future studies could investigate whether better patients' selection is associated with increased outcomes. 
Besides the trials above mentioned (Table 3), the combination of atezolizumab and bevacizumab has been testing in two other ongoing trials in the recurrent setting: NCT03353831 [68] and NCT02839707 [69].

Table 3. Clinical trials in epithelial OC, EOC

\begin{tabular}{|c|c|c|c|c|c|c|}
\hline Author & Trial//Phase & Setting & Pts $N$ & Treatment & Results & $\begin{array}{l}\text { Grade 3-4 AEs } \\
\text { Pts } N(\%)\end{array}$ \\
\hline $\begin{array}{l}\text { Matulonis et al., } \\
2019 \text { [50] }\end{array}$ & $\begin{array}{l}\text { KEYNOTE } \\
100 \\
\text { Phase II }\end{array}$ & $\begin{array}{l}\text { Advanced } \\
\text { recurrent } \\
\text { Cohort A: 1-3 } \\
\text { prior lines PFI/ } \\
\text { TFI 3-12 Mo. } \\
\text { Cohort B: 4-6 } \\
\text { prior lines PFI/ } \\
\text { TFI } \geq 3 \text { Mo. }\end{array}$ & $\begin{array}{l}\text { Cohort A: } \\
285 \\
\text { Cohort B: } \\
91\end{array}$ & $\begin{array}{l}\text { Pembrolizumab } \\
200 \text { mg q3w until } \\
2 \text { years }\end{array}$ & $\begin{array}{l}\text { Total population: } \\
\text { ORR } 8 \%, \\
\text { DCR of } 37 \% \\
\text { Cohort A: } \\
\text { ORR } 7.4 \%, \\
\text { DoR } 8.2 \text { Mo. } \\
\text { DCR } 37.2 \% \\
\text { OS NR } \\
\text { Cohort B: } \\
\text { ORR } 9.9 \% \\
\text { DoR NR } \\
\text { DCR } 37.4 \% \\
\text { OS } 17.6 \text { Mo. }\end{array}$ & $\begin{array}{l}\text { Treatment-related: } \\
\text {-fatigue } n=10(2.7) \\
\text {-anemia } n=5(1.3) \\
\text {-colitis } n=5(1.3) \\
\text { Immune-mediated: } \\
\text {-severe skin } \\
\text { reactions } n=7(1.9) \\
\text {-colitis } n=6(1.6)\end{array}$ \\
\hline $\begin{array}{l}\text { SGO } 2020 \text { Annual } \\
\text { meeting [72] }\end{array}$ & $\begin{array}{l}\text { JAVELIN } 100 \\
\text { Phase III }\end{array}$ & First line & 998 & $\begin{array}{l}6 \text { cycles } \\
\text { carboplatin } \\
\text { AUC } 5 / 6, \text { q } 3 w \\
+ \text { paclitaxel } 175 \\
\mathrm{mg} / \mathrm{mq} \text { q3w or } 80 \\
\mathrm{mg} / \mathrm{mq} \text { weekly } \\
\text { a) + avelumab } \\
10 \mathrm{mg} / \mathrm{kg} \mathrm{q} 3 \mathrm{w} \\
\text { (with CT)/q2w } \\
\text { (maintenance) } \\
\text { b) + avelumab } \\
10 \text { mg/kg q2w } \\
\text { maintenance } \\
\text { c) no avelumab }\end{array}$ & $\begin{array}{l}\text { ORR: } \\
\begin{array}{l}\text { a) } 36.0 \% \\
\text { b) } 30.4 \% \\
\text { c) } 30.4 \%\end{array}\end{array}$ & $\begin{array}{l}\text { Grade } 3-4 \text { AEs: } \\
\text { a) } 70.8 \% \\
\text { b) } 66.5 \% \\
\text { c) } 62.6 \%\end{array}$ \\
\hline $\begin{array}{l}\text { NCT02580058 } \\
{[51]}\end{array}$ & $\begin{array}{l}\text { JAVELIN } 200 \\
\text { Phase III }\end{array}$ & $\begin{array}{l}\text { Platinum } \\
\text { resistant }\end{array}$ & 566 & $\begin{array}{l}\text { a) PLD } 40 \mathrm{mg} / \mathrm{mq} \\
\text { q4w } \\
\text { b) Ave } 10 \mathrm{mg} / \mathrm{kg} \\
\text { q2w } \\
\text { c) combination of } \\
\text { both }\end{array}$ & $\begin{array}{l}\text { PFS: } \\
\text { a) } 3.5 \mathrm{Mo} . \\
\text { b) } 1.9 \mathrm{Mo} . \\
\text { c) } 3.7 \mathrm{Mo} . \\
\text { OS: } \\
\text { a) } 13.1 \mathrm{Mo} . \\
\text { b) } 11.8 \mathrm{Mo} . \\
\text { c) } 15.7 \mathrm{Mo} . \\
\text { (HR, } 0.89)\end{array}$ & $\begin{array}{l}\text { Abdominal pain: } \\
\text { a) } 3.39 \% \\
\text { b) } 4.81 \% \\
\text { c) } 3.30 \% \\
\text { Intestinal obstruction: } \\
\text { a) } 3.39 \% \\
\text { b) } 5.88 \% \\
\text { c) } 4.95 \% \\
\text { Vomiting: } \\
\text { a) } 1.69 \% \\
\text { b) } 3.74 \% \\
\text { c) } 2.20 \%\end{array}$ \\
\hline $\begin{array}{l}\text { Drew et al., } 2019 \\
\text { [57] }\end{array}$ & $\begin{array}{l}\text { MEDIOLA } \\
\text { Phase II }\end{array}$ & $\begin{array}{l}\text { BRCA-mutated } \\
\text { platinum- } \\
\text { sensitive } \\
\text { relapsed }\end{array}$ & 32 & $\begin{array}{l}\text { Olaparib } \\
\text { monotherapy } \\
300 \mathrm{mg} \text { bid } 4 \\
\text { weeks } \rightarrow \text { olaparib } \\
300 \mathrm{mg} \text { bid }+ \\
\text { durvalumab } \\
1,500 \mathrm{mg} \mathrm{IV} \mathrm{q4w}\end{array}$ & $\begin{array}{l}\text { ORR } 71.9 \% \\
28-w k \text { DCR } \\
65.6 \% \\
\text { Median PFS } \\
11.1 \text { Mo. } \\
\text { Median DoR } \\
10.2 \text { Mo. }\end{array}$ & $\begin{array}{l}\text {-anaemia } 17.6 \% \\
\text {-elevated lipase } 11.8 \% \\
\text {-neutropenia } 8.8 \% \\
\text {-lymphopenia } 8.8 \% \\
\text { Discontinuation due } \\
\text { to AEs: } \\
\text { Olaparib } 5 \text { pts } \\
\text { Durvalumab } 3 \text { pts }\end{array}$ \\
\hline
\end{tabular}


Table 3. Clinical trials in epithelial OC, EOC (continued)

\begin{tabular}{|c|c|c|c|c|c|c|}
\hline \multirow[t]{2}{*}{ Author } & \multirow[t]{2}{*}{ Trial//Phase } & \multirow[t]{2}{*}{ Setting } & \multirow[t]{2}{*}{ Pts $N$} & \multirow[t]{2}{*}{ Treatment } & \multirow[t]{2}{*}{ Results } & \multirow{2}{*}{$\begin{array}{l}\text { Grade 3-4 AEs } \\
\text { Pts } N(\%)\end{array}$} \\
\hline & & & & & & \\
\hline \multirow{7}{*}{$\begin{array}{l}\text { Konstantinopoulos } \\
\text { et al., } 2019 \text { [58] }\end{array}$} & TOPACIO & \multirow{7}{*}{$\begin{array}{l}\text { Recurrent } \\
\text { platinum- } \\
\text { resistant }\end{array}$} & \multirow[t]{7}{*}{60} & \multirow{7}{*}{$\begin{array}{l}\text { Niraparib } 200 \\
\text { mg daily + } \\
\text { pembrolizumab } \\
200 \text { mg q } 3 w\end{array}$} & ORR $18 \%$ & \multirow{3}{*}{$\begin{array}{l}\text { Treatment-related: } \\
\text {-anemia } n=11(21) \\
\text {-thrombocytopenia } n \\
=5(9)\end{array}$} \\
\hline & Phase I-II & & & & DCR $65 \%$ & \\
\hline & & & & & & \\
\hline & & & & & & -leukopenia $n=3(6)$ \\
\hline & & & & & & $\begin{array}{l}\text {-neutropenia } n= \\
2(4)\end{array}$ \\
\hline & & & & & & Immune-related AEs: \\
\hline & & & & & & $n=3(6)$ \\
\hline
\end{tabular}

Pts $N$ : patient number; Mo.: month; NR not reached

The first one is a phase III, multicenter, randomized trial evaluating the safety and efficacy of combining bevacizumab plus atezolizumab and chemotherapy, compared to bevacizumab plus placebo and chemotherapy in the relapsed disease (first and second recurrence within 6 months after platinum containing chemotherapy); the second trial is a phase II/III study assessing the combination of atezolizumab/bevacizumab with PLD.

The combination of nivolumab (anti-PD1) and bevacizumab (anti-VEGF) has been studied in a phase II trial in 38 recurrent OC heavily pre-treated ( $\geq 3$ chemotherapy lines) patients. In the overall population the objective response rate was $28.9 \%$ (40\% vs. $16.7 \%$ in the platinum-sensitive and resistant setting, respectively); the median PFS was 9.4 months (12.1 and 7.7 months in sensitive and resistant patients, respectively). Thirty-four patients (89.5\%) revealed at least one treatment-related adverse event and $23.7 \%$ a grade 3 or higher treatment-related adverse event [70].

Cediranib, an oral VEGF receptor inhibitor, has been evaluated in combination with durvalumab, an antiPDL1 inhibitor, in the recurrent OC setting, in heavily pre-treated patients. A phase I trial reported a DCR of $75 \%$ with six partial response and three stabilizations of disease. Grade 3 and 4 AEs occurred on the daily schedule, those were: pulmonary embolism $(2 / 8)$, hypertension $(2 / 8)$, diarrhea $(2 / 8)$, lymphopenia $(1 / 8)$ and pulmonary hypertension (1/8) while only hypertension (1/6) and fatigue (1/6) were present at grade 3 and 4 in the intermittent cediranib schedule. The investigators concluded that the association of durvalumab plus intermittent cediranib is tolerable and clinically active [71].

\section{Conclusion}

Immunotherapy represents a potentially promising strategy to expand the therapeutic armamentarium of gynecological malignancies and many trials are going in cervical, endometrial and OC (Table 4).

In CC, clinical data on the use of immunotherapy either as monotherapy, or in combination with chemotherapy, radiotherapy and other ICIs, appear promising; ongoing studies will better address the best setting in which this strategy will produce the higher benefit.

In EC the available data are conflicting, with some studies suggesting higher benefit in MSI-H and POLE mutated tumors, some others reporting efficacy regardless the molecular profile of the disease, especially when ICIs are combined with oral tyrosine-kinases inhibitors with antiangiogenic properties. Ongoing trials in advanced, chemo-naïve patients, combining immunotherapy with platinum-base chemotherapy, will possibly change the standard of care in this setting.

Immunotherapy as single agent and in combination with antiangiogenic agents reported disappointing results in any setting of OC disease, mostly because of the unavailability of a reliable predictive biomarker of response and, as a consequence, a bias in patient selection. Our expectations and hopes are that the ongoing trials studying the combination of ICIs with PARPis will clarify the role, if any, of immunotherapy in OC treatment. 
Table 4. Clinical trials on ICls in gynecological malignancies

\begin{tabular}{|c|c|c|c|c|}
\hline \multirow[t]{6}{*}{ Disease } & \multirow[t]{6}{*}{ Setting } & \multicolumn{3}{|l|}{ ICls } \\
\hline & & CTLA-4 & PD-1 & PD-L1 \\
\hline & & Ipilimumab & Pembrolizumab & Ave \\
\hline & & Tremelimumab & Nivolumab & Atezolizumab \\
\hline & & & Dostarlimab & Durvalumab \\
\hline & & & Cemiplimab & \\
\hline \multirow[t]{8}{*}{$\mathrm{OC}$} & NACT first-line & & ENGOT OV 43 [60] & AGO DUO [59] \\
\hline & & & FIRST [61] & \\
\hline & & & ATHENA [62] & \\
\hline & & & MITO 28 [63] & \\
\hline & ROC Plat Se & NRG-GY003 [53] & NCT02873962 [77] & ANITA [79] \\
\hline & & & & ATALANTE [80] \\
\hline & ROC Plat R & & NCT02440425 [52] & EORTC 1508 [81] \\
\hline & & & NCT02873962 [74] & NCT02484404 [82] \\
\hline \multirow[t]{7}{*}{ EC } & Advanced (III-IV) recurrent & & LEAP-001 [41] & MITO END-3 [44] \\
\hline & CT naive & & NRG-GY018 [45] & ATTEND [42] \\
\hline & & & & RUBY [43] \\
\hline & Recurrent prior CT & NCT03015129 [37] & NCT02899793 [38] & MITO END-3 [44] \\
\hline & & NCT02982486 [40] & KEYNOTE-775 [46] & ATTEND [42] \\
\hline & & NCT02834013 [73] & NCT02549209 [45] & NCT02912572 [39] \\
\hline & & & & NCT03526432 [83] \\
\hline \multirow[t]{6}{*}{$\mathrm{CC}$} & LACC & NCT01711515 [74] & MITO CERV 3 [15] & \\
\hline & & & NCT04221945 [14] & \\
\hline & Recurrent metastatic & & NRG-GY002 [75] & NCT02921269 [78] \\
\hline & & & KEYNOTE 826 [16] & BEAT [17] \\
\hline & & & REGENERON [19] & \\
\hline & & & CX 8 [76] & \\
\hline
\end{tabular}

NACT: neoadiuvant chemotherapy; ROC: recurrent epithelial ovarian cancer; Plat Se/Plat R: platinum sensitive/resistant; LACC: locally advanced cervical cancer

\section{Abbreviations}

ACT: adoptive T cell therapy

AEs: adverse events

Ave: Avelumab

CARs: chimeric antigen receptors

CC: cervical cancer

CPS: combined positive score

CR: complete response

CTLA-4: cytotoxic T-lymphocyte-associated protein 4

DCR: disease control rate

dMMR: deficient mismatch repair system

DoR: duration of response

EC: endometrial cancer

HRD: homologous recombination deficiency

ICIs: immune checkpoint inhibitors

MSI-H: microsatellite instability hypermutated

OC: ovarian cancer 
ORR: overall response rate

OS: overall survival

PARPi: poly (ADP-ribose) polymerase inhibitor

PD-1: programmed death-1

PD-L1: programmed death-ligand 1

PFI: platinum-free interval

PFS: progression free survival

PLD: pegylated liposomal doxorubicin

PR: partial response

SD: stable disease

TCRs: T cell receptors

TFI: treatment-free interval

TILs: tumor-infiltrating lymphocytes

\section{Declarations}

\section{Author contributions}

DL contributed to conception and design of the study; VC wrote the first draft of the manuscript; GD, AP, VS, MM, CN, FC, GS wrote sections of the manuscript. All authors contributed to manuscript revision, read and approved the submitted version.

\section{Conflicts of interest}

VC, MM, CN, FC declare that they have no conflicts of interest.

Outside the submitted work:

DL has served on advisory boards for Clovis Oncology, AstraZeneca, Genmab/Seattle Genetics, MSD, ImmunoGen, PharmaMar, Roche, and Tesaro/GSK, received support for travel or accommodation from AstraZeneca, GSK and Roche and institutional research funding from Merck, GSK, Clovis, Pharmamar.

GD has served on advisory board of Beigene and received support for travel and accomodation from Roche.

VS has served on advisory board of Roche, Astra Zeneca, MSD, GSK and Clovis and received support for travel and accomodation from Pharmamar, GSK, Roche.

AP worked at Astra Zeneca Medical Affair Division until Dec 2018.

GS has served on advisory boards for TESARO Bio Italy S.r.l, Johnson \& Johnson, Clovis Oncology Italy S.r.l. He received support for travel or accommodation from MSD Italy S.r.l and Clovis Oncology Italy S.r.l, and institutional research funding from MSD Italy S.r.l.

\section{Ethical approval}

Not applicable.

\section{Consent to participate}

Not applicable.

\section{Consent to publication}

Not applicable.

Availability of data and materials

Not applicable. 
Funding

Not applicable.

Copyright

(C) The Author(s) 2021.

\section{References}

1. Ventriglia J, Paciolla I, Pisano C, Cecere SC, Di Napoli M, Tambaro R, et al. Immunotherapy in ovarian, endometrial and cervical cancer: state of the art and future perspectives. Cancer Treat Rev. 2017;59:109-16.

2. Di Tucci C, Capone C, Galati G, Iacobelli V, Schiavi MC, Di Donato V, et al. Immunotherapy in endometrial cancer: new scenarios on the horizon. J Gynecol Oncol. 2019;30:e46.

3. Wu Y, Chen W, Xu ZP, Gu W. PD-L1 distribution and perspective for cancer immunotherapy-blockade, knockdown, or inhibition. Front Immunol. 2019;[Epub ahead of print].

4. Fife BT, Bluestone JA. Control of peripheral T-cell tolerance and autoimmunity via the CTLA-4 and PD-1 pathways. Immunol Rev. 2008;224:166-82.

5. Ruella M, Kalos M. Adoptive immunotherapy for cancer. Immunol Rev. 2014;257:14-38.

6. Piersma SJ. Immunosuppressive tumor microenvironment in cervical cancer patients. Cancer Microenviron. 2011;4:361-75.

7. Ott PA, Bang YJ, Piha-Paul SA, Razak ARA, Bennouna J, Soria JC, et al. T-cell-inflamed gene-expression profile, programmed death ligand 1 expression, and tumor mutational burden predict efficacy in patients treated with pembrolizumab across 20 cancers: KEYNOTE-028. J Clin Oncol. 2019;37:318-27.

8. Frenel JS, Le Tourneau C, O’Neil B, Ott PA, Piha-Paul SA, Gomez-Roca C, et al. Safety and efficacy of pembrolizumab in advanced, programmed death ligand 1-positive cervical cancer: results from the phase Ib KEYNOTE-028 trial. J Clin Oncol. 2017;35:4035-41.

9. Ott PA, Bang YJ, Berton-Rigaud D, Elez E, Pishvaian MJ, Rugo HS, et al. Safety and antitumor activity of pembrolizumab in advanced programmed death ligand 1-positive endometrial cancer: results from the KEYNOTE-028 study. J Clin Oncol. 2017;35:2535-41.

10. Varga A, Piha-Paul S, Ott PA, Mehnert JM, Berton-Rigaud D, Morosky A, et al. Pembrolizumab in patients with programmed death ligand 1-positive advanced ovarian cancer: Analysis of KEYNOTE-028. Gynecol Oncol. 2019;152:243-50.

11. Chung HC, Ros W, Delord JP, Perets R, Italiano A, Shapira-Frommer R, et al. Efficacy and safety of pembrolizumab in previously treated advanced cervical cancer: results from the phase II KEYNOTE-158 study. J Clin Oncol. 2019;37:1470-8.

12. Naumann RW, Hollebecque A, Meyer T, Devlin MJ, Oaknin A, Kerger J, et al. Safety and efficacy of nivolumab monotherapy in recurrent or metastatic cervical, vaginal, or vulvar carcinoma: results from the phase I/ II CheckMate 358 trial. J Clin Oncol. 2019;37:2825-34.

13. Naumann RW, Oaknin A, Meyer T, Lopez-Picazo JM, Lao C, Bang Y, et al. Efficacy and safety of nivolumab (Nivo) + ipilimumab (Ipi) in patients (pts) with recurrent/metastatic (R/M) cervical cancer: results from CheckMat 358. Ann Oncol. 2019;30 Suppl 5:V851-934.

14. Study of chemoradiotherapy with or without pembrolizumab (MK-3475) for the treatment of locally advanced cervical cancer (MK-3475-A18/KEYNOTE-A18/ENGOT-cx11) [Internet]. Bethesda (MD): National Library of Medicine (US); c2020 [updated 2021 Feb 1; cited 2020 Apr 27]. Available from: https://clinicaltrials.gov/ct2/show/NCT04221945?term=04221945\&draw=2\&rank=1

15. Carboplatin-paclitaxel-pembrolizumab in neoadjuvant treatment of locally advanced cervical cancer [Internet]. Bethesda (MD): National Library of Medicine (US); c2020 [updated 2020 Jan 3; cited $2020 \mathrm{Apr}$ 27]. Available from: https://clinicaltrials.gov/ct2/show/NCT04238988?term=cerv+3\&draw=2\&rank=1 
16. Efficacy and safety study of first-line treatment with pembrolizumab (MK-3475) plus chemotherapy versus placebo plus chemotherapy in women with persistent, recurrent, or metastatic cervical cancer (MK-3475-826/KEYNOTE-826) [Internet]. Bethesda (MD): National Library of Medicine (US); c2018 [updated 2020 Nov 13; cited 2020 Apr 27]. Available from: https://clinicaltrials.gov/ct2/show/ NCT03635567?term=keynote-826\&draw=2\&rank=1

17. Grau JF, Farinas-Madrid L, Oaknin A. A randomized phase III trial of platinum chemotherapy plus paclitaxel with bevacizumab and atezolizumab versus platinum chemotherapy plus paclitaxel and bevacizumab in metastatic (stage IVB), persistent, or recurrent carcinoma of the cervix: the BEATcc study (ENGOT-Cx10/GEICO 68-C/JGOG1084/GOG-3030). Int J Gynecol Cancer. 2020;30:139-43.

18. Safety and efficacy of tisotumab vedotin monotherapy \& in combination with other cancer agents in subjects with cervical cancer [Internet]. Bethesda (MD): National Library of Medicine (US); c2018 [updated 2020 Dec 17; cited 2020 Apr 27]. Available from: https://clinicaltrials.gov/ct2/show/ NCT03786081?term=tisotumab+vedotin\&cond=cervical+cancer\&draw=2\&rank=2

19. Study of cemiplimab in adults with cervical cancer [Internet]. Bethesda (MD): National Library of Medicine (US); c2017 [updated 2020 Jul 15; cited 2020 Apr 27]. Available from: https://clinicaltrials. gov/ct2/show/NCT03257267?term=regn\&cond=Cervical+Cancer\&draw=2\&rank=1

20. Stevanović S, Draper LM, Langhan MM, Campbell TE, Kwong ML, Wunderlich JR, et al. Complete regression of metastatic cervical cancer after treatment with human papillomavirus-targeted tumor-infiltrating $\mathrm{T}$ cells. J Clin Oncol. 2015;33:1543-50.

21. Study of ADXS11-001 in subjects with high risk locally advanced cervical cancer [Internet]. Bethesda (MD): National Library of Medicine (US); c2016 [updated 2020 Aug 12; cited 2020 Apr 27]. Available from: https://clinicaltrials.gov/ct2/show/NCT02853604?term=02853604\&draw=2\&rank=1

22. Phase 1-2 study of ADXS11-001 or MEDI4736 alone or combo in cervical or HPV + head \& neck cancer [Internet]. Bethesda (MD): National Library of Medicine (US); c2014 [updated 2020 Feb 19; cited 2020 Apr 27]. Available from: https://clinicaltrials.gov/ct2/show/ NCT02291055?term $=02291055 \&$ draw $=2 \&$ rank=1

23. Basu P, Mehta A, Jain M, Gupta S, Nagarkar RV, John S, et al. A randomized phase 2 study of ADXS11001 Listeria monocytogenes-listeriolysin 0 immunotherapy with or without cisplatin in treatment of advanced cervical cancer. Int J Gynecol Cancer. 2018;28:764-72.

24. Vora C, Gupta S. Targeted therapy in cervical cancer. ESMO Open. 2019;3 Suppl 1:e000462.

25. Lheureux S, Butler MO, Clarke B, Cristea MC, Martin LP, Tonkin KS, et al. A phase I/II study of ipilimumab in women with metastatic or recurrent cervical carcinoma: a study of the Princess Margaret and Chicago N01 Consortia. J Clin Oncol. 2015;33 Suppl 15:3061.

26. Siegel RL, Miller KD, Jemal A. Cancer statistics, 2018. CA Cancer J Clin. 2018;68:7-30.

27. Howitt BE, Shukla SA, Sholl LM, Ritterhouse LL, Watkins JC, Rodig S, et al. Association of polymerase e-mutated and microsatellite-instable endometrial cancers with neoantigen load, number of tumorinfiltrating lymphocytes, and expression of PD-1 and PD-L1. JAMA Oncol. 2015;1:1319-23.

28. Green AK, Feinberg J, Makker V. A review of immune checkpoint blockade therapy in endometrial cancer. Am Soc Clin Oncol Educ Book. 2020;40:1-7.

29. Herzog TJ, Arguello D, Reddy SK, Gatalica Z. PD-1 and PD-L1 expression in 1599 gynecological cancers: implications for immunotherapy. Gynecol Oncol. 2015;137 Suppl 1:204-5.

30. Highlights of prescribing information. These highlights do not include all the information needed to use KEYTRUDA safely and effectively. See full prescribing information for KEYTRUDA [Internet]. Seattle: U.S. Food and Drug Administration; c2014 [cited 2020 May 11]. Available from: https://www.accessdata. fda.gov/drugsatfda_docs/label/2018/125514s034lbl.pdf 
31. Makker V, Rasco D, Vogelzang NJ, Brose MS, Cohn AL, Mier J, et al. Lenvatinib plus pembrolizumab in patients with advanced endometrial cancer: an interim analysis of a multicentre, open-label, single-arm, phase 2 trial. Lancet Oncol. 2019;20:711-8.

32. Pembrolizumab/lenvatinib in advanced endometrial carcinoma without microsatellite instabilityhigh or mismatch repair-deficient disease [Internet]. Alexandria: ASCO. 2018 Oct [cited 2020 Aug 8 ]. Available from: https://www.ascopost.com/issues/october-25-2019/pembrolizumablenvatinib-inadvanced-endometrial-carcinoma-without-msi-h-or-mmr-d-disease/

33. NIPH Clinical Trials Search [Internet]. Japan: National Institute of Public Health; c2016 [cited 2020 Apr 28]. Available from: https://rctportal.niph.go.jp/en/detail?trial_id=JapicCTI-163212

34. Study of TSR-042, an anti-programmed cell death-1 receptor (PD-1) monoclonal antibody, in participants with advanced solid tumors [Internet]. Bethesda (MD): National Library of Medicine (US); c2016 [updated 2020 June 11; cited 2020 Jul 25]. Available from: https://clinicaltrials.gov/ct2/show/ NCT02715284?term=NCT02715284\&draw $=2 \&$ rank=1

35. Oaknina A, Tinkerb AV, Gilbertc L, Samouëliand V, Mathewse CA, Brownf J, et al. Safety and efficacy of the anti-PD-1 monoclonal antibody dostarlimab in patients with recurrent or advanced dMMR endometrial cancer. Society of Gynecologic Oncology 2020 Annual Meeting on Women's Cancer. 2020 March 28-31, Toronto, Canada.

36. A study of atezolizumab (an engineered anti-programmed death-ligand 1 [PDL1] antibody) to evaluate safety, tolerability and pharmacokinetics in participants with locally advanced or metastatic solid tumors [Internet]. Bethesda (MD): National Library of Medicine (US); c2011 [updated 2018 Dec 11; cited 2020 Apr 28]. Available from: https://clinicaltrials.gov/ct2/show/ NCT01375842?term=NCT01375842\&draw $=2 \&$ rank=1

37. Rubinstein MM, Caird I, Zhou Q, Iasonos A, Friedman CF, Cadoo KA, et al. A phase II trial of durvalumab with or without tremelimumab in patients with persistent or recurrent endometrial carcinoma and endometrial carcinosarcoma. J Clin Oncol. 2019;37 Suppl 15:5582.

38. Pembrolizumab in ultramutated and hypermutated endometrial cancer [Internet]. Bethesda (MD): National Library of Medicine (US); c2016 [updated 2020 Apr 13; cited 2020 Apr 22]. Available from: https://clinicaltrials.gov/ct2/show/NCT02899793?term=02899793\&draw=2\&rank=1

39. Avelumab in patients with MSS, MSI-H and POLE-mutated recurrent or persistent endometrial cancer and of avelumab/talazoparib in patients with MSS recurrent or persistent endometrial cancer [Internet]. Bethesda (MD): National Library of Medicine (US); c2016 [updated 2020 Jun 2; cited 2020 Apr 28]. Available from: https://clinicaltrials.gov/ct2/show/NCT02912572?term=02912572\&draw=2\&rank=1

40. A phase II of nivolumab plus ipilimumab in non-resectable sarcoma and endometrial carcinoma [Internet]. Bethesda (MD): National Library of Medicine (US); c2016 [updated 2017 Nov 1; cited 2020 Apr 22]. Available from: https://clinicaltrials.gov/ct2/show/NCT02982486?term=02982486\&draw=2\&rank=1

41. Pembrolizumab (MK-3475) plus lenvatinib (E7080/MK-7902) versus chemotherapy for endometrial carcinoma (ENGOT-en9/MK-7902-001) (LEAP-001) [Internet]. Bethesda (MD): National Library of Medicine (US); c2019 [updated 2021 Jan 29; cited 2020 Apr 28]. Available from: https://clinicaltrials. gov/ct2/show/NCT03884101?term $=03884101 \&$ draw $=2 \&$ rank $=1$

42. Atezolizumab trial in endometrial cancer-AtTEnd (AtTEnd) [Internet]. Bethesda (MD): National Library of Medicine (US); c2018 [updated 2020 Nov 13; cited 2020 Apr 28]. Available from: https://clinicaltrials. gov/ct2/show/NCT03603184?term=03603184\&draw=2\&rank=1

43. A study to evaluate dostarlimab plus carboplatin-paclitaxel versus placebo plus carboplatin-paclitaxel in participants with recurrent or primary advanced endometrial cancer (RUBY) [Internet]. Bethesda (MD): National Library of Medicine (US); c2019 [updated 2021 Jan 22; cited 2020 Apr 22]. Available from: https://clinicaltrials.gov/ct2/show/NCT03981796 
44. Carboplatin, paclitaxel with or without avelumab in advanced or recurrent endometrial cancer [Internet]. Bethesda(MD):NationalLibraryofMedicine(US);c2018 [updated2018Apr20;cited2020Apr28].Available from: https://clinicaltrials.gov/ct2/show/NCT03503786?term=mito+end+3\&draw=2\&rank=1

45. Pembro/carbo/taxol in endometrial cancer [Internet]. Bethesda (MD): National Library of Medicine (US); c2015 [updated 2021 Jan 6; cited 2020 Apr 28]. Available from: https://clinicaltrials.gov/ct2/ show/NCT02549209?term $=02549209 \&$ draw $=2 \&$ rank=1

46. Lenvatinib in combination with pembrolizumab versus treatment of physician's choice in participants with advanced endometrial cancer (MK-3475-775/E7080-G000-309 Per Merck Standard Convention [KEYNOTE-775]) [Internet]. Bethesda (MD): National Library of Medicine (US); c2018 [updated 2020 Dec 4; cited 2020 Apr 26]. Available from: https://clinicaltrials.gov/ct2/show/ NCT03517449?term $=03517449$ \&draw $=2 \&$ rank $=1$

47. Marabelle A, Le DT, Ascierto PA, Di Giacomo AM, De Jesus-Acosta A, Delord JP, et al. Efficacy of pembrolizumab in patients with noncolorectal high microsatellite instability/mismatch repair-deficient cancer: results from the phase II KEYNOTE-158 study. J Clin Oncol. 2020;38:1-10.

48. Oaknin A, Ellard SL, Leath C, Moreno C, Kristeleit R, Guo W, et al. Preliminary safety, efficacy, and pharmacokinetic and pharmacodynamic characterisation from GARNET, a phase I clinical trial of the anti-PD-1 monoclonal antibody TSR-042 in patients with recurrent or advanced microsatellite instability-high endometrial cancer. EMJ Oncol. 2018;6:71-3.

49. Hamanishi J, Mandai M, Iwasaki M, Okazaki T, Tanaka Y, Yamaguchi K, et al. Programmed cell death 1 ligand 1 and tumor-infiltrating CD8+ T lymphocytes are prognostic factors of human ovarian cancer. Proc Natl Acad Sci USA. 2007;104:3360-5.

50. Matulonis UA, Shapira-Frommer R, Santin AD, Lisyanskaya AS, Pignata S, Vergote I, et al. Antitumor activity and safety of pembrolizumab in patients with advanced recurrent ovarian cancer: results from the phase II KEYNOTE-100 study. Ann Oncol. 2019;30:1080-7.

51. A study of avelumab alone or in combination with pegylated liposomal doxorubicin versus pegylated liposomal doxorubicin alone in patients with platinum resistant/refractory ovarian cancer (JAVELIN Ovarian 200) [Internet]. Bethesda (MD): National Library of Medicine (US); c2015 [updated 2019 Nov 19; cited 2020 Apr 22]. Available from: https://clinicaltrials.gov/ct2/show/ NCT02580058?term=javelin+ovarian\&draw $=2 \&$ rank $=3$

52. Dose dense paclitaxel with pembrolizumab (MK-3475) in platinum resistant ovarian cancer [Internet]. Bethesda (MD): National Library of Medicine (US); c2015 [updated 2020 Nov 5; cited 2020 Apr 27]. Available from: https://clinicaltrials.gov/ct2/show/NCT02440425?term=02440425\&draw=2\&rank=1

53. Addition of a CTLA-4-targeted therapy to a checkpoint inhibitor in ovarian cancer [Internet]. Alexandria: ASCO. 2018 Oct [cited 2020 Apr 28]. Available from: https://www.ascopost.com/News/59329

54. Avelumab in previously untreated patients with epithelial ovarian cancer (JAVELIN OVARIAN 100) [Internet]. Bethesda (MD): National Library of Medicine (US); c2016 [updated 2019 Dec 18; cited 2020 Apr 22]. Available from: https://clinicaltrials.gov/ct2/show/results/ NCT02718417?term=javelin+ovarian\&draw=2\&rank=2

55. Stewart RA, Pilie PG, Yap TA. Development of PARP and immune-checkpoint inhibitor combinations. Cancer Res. 2018;78:6717-25.

56. Higuchi T, Flies DB, Marjon NA, Mantia-Smaldone G, Ronner L, Gimotty PA, et al. CTLA-4 blockade synergizes therapeutically with PARP inhibition in BRCA1-deficient ovarian cancer. Cancer Immunol Res. 2015;3:1257-68.

57. Drew Y, Kaufman B, Banerjee S, Lortholary A, Hong SH, Park YH, et al. Phase II study of olaparib + durvalumab (MEDIOLA): updated results in germline BRCA-mutated platinum-sensitive relapsed (PSR) ovarian cancer (OC). Immunother Cancer. 2019;30 Suppl 5:V485-6. 
58. Konstantinopoulos PA, Waggoner S, Vidal GA, Mita M, Moroney JW, Holloway R, et al. Single-arm phases 1 and 2 trial of niraparib in combination with pembrolizumab in patients with recurrent platinumresistant ovarian carcinoma. JAMA Oncol. 2019;5:1141-9.

59. Durvalumab treatment in combination with chemotherapy and bevacizumab, followed by maintenance durvalumab, bevacizumab and olaparib treatment in advanced ovarian cancer patients. (DUO-O) [Internet]. Bethesda (MD): National Library of Medicine (US); c2018 [updated 2021 Jan 11; cited 2020 Mar 3]. Available from: https://clinicaltrials.gov/ct2/show/NCT03737643

60. Study of chemotherapy with pembrolizumab (MK-3475) followed by maintenance with olaparib (MK7339) for the first-line treatment of women with BRCA non-mutated advanced epithelial ovarian cancer (EOC) (MK-7339-001/KEYLYNK-001/ENGOT-ov43) [Internet]. Bethesda (MD): National Library of Medicine (US); c2018 [updated 2021 Jan 29; cited 2020 Mar 3]. Available from: https://clinicaltrials. gov/ct2/show/NCT03740165?term=a+randomized+phase+3\%2C+double-blind+study+of+chemothe rapy+with+or+without+pembrolizumab+followed+by+maintenance+with+olaparib\&draw=2\&rank=1

61. A phase 3 comparison of platinum-based therapy with TSR-042 and niraparib versus standard of care (SOC) platinum-based therapy as first-line treatment of stage III or IV nonmucinous epithelial ovarian cancer (FIRST) [Internet]. Bethesda (MD): National Library of Medicine (US); c2018 [updated 2021 Jan 28; cited 2020 Mar 3]. Available from: https://clinicaltrials.gov/ct2/show/ NCT03602859?term=FIRST \&cond=Ovarian+Cancer\&draw $=2$

62. Astudy in ovarian cancer patients evaluating rucapariband nivolumab as maintenance treatmentfollowing response to front-line platinum-based chemotherapy (ATHENA) [Internet]. Bethesda (MD): National Library of Medicine (US); c2018 [updated 2020 Oct 30; cited 2020 Apr 28]. Available from: https:// clinicaltrials.gov/ct2/show/NCT03522246?term=athena\&cond=0varian+Cancer\&draw=2\&rank=1

63. Pembrolizumab with chemotherapy in front line advanced ovarian, primary peritoneal and fallopian tube cancer (MITO28MaNGOov4) [Internet]. Bethesda (MD): National Library of Medicine (US); c2018 [updated 2018 Apr 12; cited 2020 Apr 28]. Available from: https://clinicaltrials.gov/ct2/show/ NCT03410784?term=MITO+28\&cond=0varian+Cancer\&draw=2\&rank=1

64. Chen DS, Mellman I. Oncology meets immunology: the cancer-immunity cycle. Immunity. 2013;39:1-10.

65. Gao X, McDermott DF. Combinations of bevacizumab with immune checkpoint inhibitors in renal cell carcinoma. Cancer J. 2018;24:171-9.

66. Zhang L, Chen Y, Li F, Bao L, Liu W. Atezolizumab and bevacizumab attenuate cisplatin resistant ovarian cancer cells progression synergistically via suppressing epithelial-mesenchymal transition. Front Immunol. 2019;10:867.

67. Moore KN, Pignata S. Trials in progress: IMagyn050/GOG 3015/ENGOT-OV39. A Phase III, multicenter, randomized study of atezolizumab versus placebo administered in combination with paclitaxel, carboplatin, and bevacizumab to patients with newly-diagnosed stage III or stage IV ovarian, fallopian tube, or primary peritoneal cancer. Int J Gynecol Cancer. 2019;[Epub ahead of print].

68. Harter P, Pautier P, Van Nieuwenhuysen E, Reuss A, Redondo A, Lindemann K, et al. Atezolizumab in combination with bevacizumab and chemotherapy versus bevacizumab and chemotherapy in recurrent ovarian cancer - a randomized phase III trial (AGO-OVAR 2.29/ENGOT-ov34). Int J Gynecol Cancer. 2020;30:1997-2001.

69. Pegylated liposomal doxorubicin hydrochloride with atezolizumab and/or bevacizumab in treating patients with recurrent ovarian, fallopian tube, or primary peritoneal cancer [Internet]. Bethesda (MD): National Library of Medicine (US); c2016 [updated 2021 Jan 22; cited 2020 Oct 17]. Available from: https://clinicaltrials.gov/ct2/show/NCT02839707?term=NCT02839707\&draw=2\&rank=1

70. Liu JF, Herold C, Gray KP, Penson RT, Horowitz N, Konstantinopoulos PA, et al. Assessment of combined nivolumab and bevacizumab in relapsed ovarian cancer: a phase 2 clinical trial. JAMA Oncol. 2019;5:1731-8.

71. Lee JM, Cimino-Mathews A, Peer CJ, Zimmer A, Lipkowitz S, Annunziata CM, et al. Safety \& clinical activity of the programmed death-ligand 1 inhibitor durvalumab in combination with poly (ADP-Ribose) 
polymerase inhibitor olaparib or vascular endothelial growth factor receptor 1-3 inhibitor cediranib in women's cancers: a dose-escalation, phase I study. J Clin Oncol. 2017;35:2193-202.

72. Ledermann JA, Colombo N, Oza AM. Avelumab in combination with and/or following chemotherapy vs. chemotherapy alone in patients with previously untreated epithelial ovarian cancer: results from the phase 3 JAVELIN OVARIAN 100 trial. Proceedings of the Society of Gynecologic Oncology 2020 Annual Meetingon Women's Cancer; 2020 March 28-31; Toronto, ON, Canada.

73. Nivolumab and ipilimumab in treating patients with rare tumors [Internet]. Bethesda (MD): National Library of Medicine (US); c2016 [updated 2021 Feb 2; cited 2020 Apr 22]. Available from: https:// clinicaltrials.gov/ct2/show/NCT02834013?term=NCT02834013\&draw=2\&rank=1

74. Chemoradiation therapy and ipilimumab in treating patients with stages IB2-IIB or IIIBIVA cervical cancer [Internet]. Bethesda (MD): National Library of Medicine (US); c2012 [updated 2020 Sep 2; cited 2020 Apr 28]. Available from: https://clinicaltrials.gov/ct2/show/ NCT01711515?term=NCT01711515\&draw=2\&rank=1

75. Santin A, Deng W, Frumovitz MM, Huh WH, Khleif S, Lankes HA, et al. A phase II evaluation of nivolumab, a fully human antibody against PD-1, in the treatment of persistent or recurrent cervical cancer. J Clin ncol. 2018; 36 Suppl 15:5536.

76. Vergote I, Concin N, Mirza MR, Andreassen CM, Lorusso D, Gennigens CN, et al. Phase Ib/II trial of tisotumab vedotin (TV) \pm bevacizumab (BEV), pembrolizumab (PEM), or carboplatin (CBP) in recurrent or metastatic cervical cancer (innovaTV 205/ENGOT-cx8/GOG-3024). J Clin Oncol. 2020;38 Suppl 15:TPS6095.

77. A phase II study of nivolumab/ bevacizumab/rucaparib [Internet]. Bethesda (MD): National Library of Medicine (US); c2016 [updated 2021 Feb 3; cited 2020 Apr 28]. Available from: https://clinicaltrials. gov/ct2/show/NCT02873962?term $=02873962 \&$ draw $=2 \&$ rank $=1$

78. Atezolizumab and bevacizumab in treating patients with recurrent, persistent, or metastatic cervical cancer [Internet]. Bethesda (MD): National Library of Medicine (US); c2016 [updated 2021 Jan 20; cited 2020 Apr 28]. Available from: https://clinicaltrials.gov/ct2/show/ NCT02921269?term $=02921269$ \&draw $=2$ \&rank=1

79. Platinum-based chemotherapy with atezolizumab and niraparib in patients with recurrent ovarian cancer (ANITA) [Internet]. Bethesda (MD): National Library of Medicine (US); c2018 [updated 2020 Nov 4; cited 2020 Apr 28]. Available from: https://clinicaltrials.gov/ct2/show/ NCT03598270?term=anita\&cond=0varian+Cancer\&draw=2\&rank=1

80. ATALANTE: atezolizumab vs. placebo phase III study in late relapse ovarian cancer treated with chemotherapy + bevacizumab [Internet]. Bethesda (MD): National Library of Medicine (US); c2016 [updated 2021 Jan 22; cited 2020 Apr 22]. Available from: https://clinicaltrials.gov/ct2/show/ NCT02899793?term=NCT02899793\&draw $=2 \&$ rank=1

81. Anti-programmed cell death-1 ligand 1 (aPDL-1) antibody atezolizumab, bevacizumab and acetylsalicylic acid in recurrent platinum resistant ovarian cancer [Internet]. Bethesda (MD): National Library of Medicine (US); c2016 [updated 2020 Jul 31; cited 2020 Apr 22]. Available from: https://clinicaltrials. gov/ct2/show/NCT02659384?term=EORTC+1508\&cond=ovarian+cancer\&draw=1\&rank=1

82. Phase I/II study of the anti-programmed death ligand-1 antibody MEDI4736 in combination with olaparib and/or cediranib for advanced solid tumors and advanced or recurrent ovarian, triple negative breast, lung, prostate and colorectal cancers [Internet]. Bethesda (MD): National Library of Medicine (US); c2015 [updated 2021 Jan 26; cited 2020 Dec 12]. Available from: https://clinicaltrials.gov/ct2/ show/NCT02484404?term=NCT02484404\&draw=2\&rank=1

83. Phase II study of atezolizumab + bevacizumab in endometrial cancer [Internet]. Bethesda (MD): National Library of Medicine (US); c2018 [updated 2020 Jul 1; cited 2020 Apr 26]. Available from: https:// clinicaltrials.gov/ct2/show/NCT03526432?term $=03526432 \&$ draw=2\&rank=1 